\title{
Níveis de Lisina Digestível para Frangos de Corte Machos na Fase de 22 a 42 Dias de Idade ${ }^{1}$ Giane da Silva Conhalato ${ }^{2}$, Juarez Lopes Donzele ${ }^{3}$, Luiz Fernando Teixeira Albino ${ }^{3}$, Rita Flávia
${\text { Miranda de } \text { Oliveira }^{3} \text {, Dalton de Oliveira Fontes }}^{4}$
}

RESUMO - O objetivo deste experimento foi determinar a exigência de lisina digestível para frangos de corte machos no período de 22 a 42 dias de idade. Quatrocentos e cinqüenta frangos de corte machos Hubbard, com peso médio inicial de $631 \mathrm{~g}$, foram distribuídos em delineamento experimental de blocos casualizados, com cinco tratamentos, seis repetições e 15 aves por unidade experimental. Os tratamentos corresponderam à ração basal com 19,64\% de proteína bruta e $3100 \mathrm{kcal}$ de EM/kg, suplementada com cinco níveis de L-lisina, resultando em rações com 0,$80 ; 0,86 ; 0,91 ; 0,97 ;$ e 1,02\% de lisina digestível. A digestibilidade verdadeira dos aminoácidos na dieta basal foi determinada por meio de ensaio de digestibilidade com galos Leghorn cecectomizados. Houve efeito dos níveis de lisina digestível da ração sobre ganho de peso (GP), consumo de ração, conversão alimentar (CA) e consumo de lisina, mas não houve efeito sobre a concentração de ácido úrico no soro sangüíneo, na composição química da carcaça e no rendimento de carcaça, incluindo rendimento de peito e coxa-sobrecoxa. Com base nos resultados de GP e CA, a exigência de lisina digestível foi estimada em 1,02 e 0,98\%, respectivamente.

Palavras-chave: lisina, frangos de corte, fase em terminação, machos

\section{Levels of Digestible Lysine for Male Broiler Chickens from 22 to 42 Days}

\begin{abstract}
The objective of this experiment was to determine the digestible lysine requirement for male broilers in the period from 22 to 42 days. Four hundred and sixty male broilers Hubbard, with an initial average weight of $631 \mathrm{~g}$, were allotted in a randomized block experimental design with five treatments, six replicates and 15 birds by experimental unit. The treatments corresponded to five L-lysine levels supplemented to a basal diet with $19,64 \%$ of crude protein and $3100 \mathrm{kcal}$ of $\mathrm{ME} / \mathrm{Kg}$ resulting in diets with $.80, .86, .91, .97$, and $1.02 \%$ digestible lysine. The true amino acid digestibility in the basal diet was determined by means of a digestibility trial with cecectomized Leghorn roosters. There was effect of digestible lysine levels in the diet on the weight gain (WG), diet intake, feed:gain ratio (F:G) and lysine intake, but there was no effect on the uric acid concentration in the blood serum, in the carcass chemical composition and carcass yield, including breast and hind quarter yield. Based on the WG and F:G results, the digestible lysine requirements was estimated in 1.02 and $.98 \%$, respectively.
\end{abstract}

Key Words: lysine, broiler chicks, finishing phase, male

\section{Introdução}

Basicamente, as rações formuladas para aves utilizam o milho e o farelo de soja como fonte de energia e proteína, respectivamente, resultando geralmente em rações deficientes em aminoácidos essenciais como lisina e metionina.

Sabe-se que, entre os aminoácidos essenciais, a lisina constitui o principal aminoácido de referência, ou seja, pode ser utilizada para o estabelecimento da exigência dos demais aminoácidos, expressos como percentagem do valor da lisina. O estabelecimento da exigência de lisina, principalmente, em termos de lisina digestível, nas diversas fases de produção animal, tornou-se prioritário.

De acordo com ROSTAGNO (1990), aves na fase de crescimento requerem $0,306 \%$ de lisina total por $1000 \mathrm{kcal}$ de EM, enquanto o NATIONAL RESEARCH COUNCIL - NRC (1994) preconiza $0,313 \%$ de lisina total por $1000 \mathrm{kcal}$ de EM. No entanto, SCHEUERMANN et al. (1993) obtiveram melhores resultados de desempenho de frangos, na fase de crescimento ( 22 a 42 dias de idade), com níveis de lisina total variando entre 0,85 e $0,89 \%$. HAN e BAKER (1994) recomendam $0,85 \%$ para máximo ganho de peso e $0,89 \%$ de lisina digestível para melhor conversão alimentar para frangos de corte na fase de crescimento (21 a 42 dias de idade). Entretanto, recomendações de exigência de lisina em termos de lisina digestível são ainda escassas.

Em função das variações entre os valores de exigência de lisina e da escassez de recomendações, 
em termos de lisina digestível para frangos de corte na fase de crescimento, objetivou-se determinar a exigência de lisina digestível para frangos de corte machos no período de 22 a 42 dias de idade.

\section{Material e Métodos}

O experimento foi conduzido na Seção de Avicultura do Departamento de Zootecnia, do Centro de Ciências Agrárias da Universidade Federal de Viçosa, no período de 10 de janeiro a 31 de janeiro de 1997.

Durante todo o período experimental, foi adotado o programa de luz contínuo - 24 horas de luz natural + artificial.

As variáveis temperatura e umidade relativa do ar, durante o período experimental, foram registradas por meio de termômetros de máxima e mínima e de bulbo úmido e bulbo seco, respectivamente, instalados no interior do galpão. As temperaturas máxima e mínima médias do ar e umidade relativa foram de 28,6 $\pm 0,3^{\circ} \mathrm{C} ; 21,1 \pm 0,1^{\circ} \mathrm{C}$; e $88,7 \pm 3,27 \%$, respectivamente, para o período de 22 a 28 dias; $28,4 \pm 0,5^{\circ} \mathrm{C}$; $21,0 \pm 0,3^{\circ} \mathrm{C}$; e $87,0 \pm 4,00 \%$, respectivamente, para o período de 29 a 35 dias; e $29,2 \pm 0,1^{\circ} \mathrm{C} ; 21,5 \pm 0,4^{\circ} \mathrm{C}$; e $85,3 \pm 3,27 \%$, respectivamente, para o período de 36 a 42 dias de idade.

Foram utilizados 450 frangos de corte machos da linhagem Hubbard, no período de 22 a 42 dias de idade, com peso médio inicial de $631 \mathrm{~g}$. Durante o período de 1 a 21 dias, as aves foram criadas recebendo ração comercial, sendo empregado manejo tradicional, como descrito por ÀVILA et al. (1992).

Os animais receberam ração à base de milho, farelo de soja e glúten de milho, com 19,64\% PB e $3100 \mathrm{kcal}$ de EM (Tabela 1), formulada para atender às exigências nutricionais das aves em proteína, energia, cálcio e fósforo, segundo ROSTAGNO et al. (1996), e aminoácidos totais, exceto lisina, segundo o NATIONAL RESEARCH COUNCIL - NRC (1994). A ração basal foi suplementada com cinco níveis de L-lisina $\mathrm{HCl} 78,4 \%(0,00 ; 0,07 ; 0,14 ; 0,21$ e $0,28 \%)$ em substituição ao caulim, resultando em rações com 0,88 e $0,80 \% ; 0,94$ e $0,86 \% ; 1,00$ e $0,91 \% ; 1,06$ e $0,97 \%$ e 1,12 e $1,02 \%$ de lisina total e digestível, respectivamente. A composição dos ingredientes da ração em aminoácidos totais e da ração basal em aminoácidos totais e digestíveis encontra-se na Tabela 2. A digestibilidade dos aminoácidos sintéticos adicionados à ração foi considerada $100 \%$.

A digestibilidade verdadeira dos aminoácidos na ração basal foi determinada por meio de ensaio de digestibilidade, utilizando-se oito galos Leghorn cecectomizados com peso médio de $2459 \mathrm{~g}$, sendo que quatro receberam a ração basal e quatro permaneceram em jejum durante todo o período experimental. Empregou-se o método da alimentação precisa ou alimentação forçada, desenvolvido por SIBBALD (1976); o período de jejum, a quantidade fornecida de ração e o período de coletada das excretas seguiram metodologia descrita por PUPA (1995). As excretas recolhidas diariamente foram armazenadas em frascos de vidro com tampas e colocadas em freezer $\left(-10^{\circ} \mathrm{C}\right)$ para análise posterior.

As análises dos aminoácidos na ração basal, nos ingredientes (milho, farelo de soja e glúten de milho) e nas excretas, foram realizadas no Laboratório da Guabi - Mogiana Alimentos S/A - Campinas, SP,

Tabela 1 - Composição percentual da ração basal Table 1 - Percent composition of basal diet

\begin{tabular}{|c|c|}
\hline Ingrediente (Ingredient) & $(\%)$ \\
\hline Milho (Corn) & 61,536 \\
\hline Farelo de soja (Soybean meal) & 25,006 \\
\hline Glúten de milho (Corn gluten) & 6,500 \\
\hline Fosfato bicálcico (Dicalcium phosphate) & 1,387 \\
\hline Calcário (Limestone) & 1,427 \\
\hline Óleo (Oil) & 2,179 \\
\hline $\operatorname{Sal}($ Salt $)$ & 0,409 \\
\hline Mistura vitamínica (Vitamin mix) ${ }^{1}$ & 0,100 \\
\hline Mistura mineral (Mineral mix) ${ }^{2}$ & 0,050 \\
\hline BHT & 0,010 \\
\hline Cocciden & 0,050 \\
\hline Cloreto de colina (Coline chlorate) & 0,125 \\
\hline Bacitracina de zinco (Zinc bacitracine) & 0,020 \\
\hline Caulin & 1,036 \\
\hline $\mathrm{L}-\mathrm{Lisina} \mathrm{HCl}($ L-Lysine $)(78,4 \%)$ & 0,000 \\
\hline DL - Metionina (DL-Methionine) $(99 \%)$ & 0,082 \\
\hline L-Treonina (L-Threonine) $(98,5 \%)$ & 0,083 \\
\hline \multicolumn{2}{|l|}{ Composição calculada } \\
\hline \multicolumn{2}{|l|}{ Calculated composition } \\
\hline Lisina total (Total lysine), $\%$ & 0,880 \\
\hline Lisina digestível (Digestible lysine), \% & 0,800 \\
\hline Proteína bruta (Crude protein), \% & 19,640 \\
\hline $\mathrm{EM}(\mathrm{kcal} / \mathrm{kg})$ & 3100 \\
\hline Cálcio (Calcium), \% & 0,918 \\
\hline Fósforo disponível (Available phosphorus), \% & 0,387 \\
\hline Sódio (Sodium), \% & 0,200 \\
\hline \multicolumn{2}{|c|}{$\begin{array}{l}{ }^{1} \text { Conteúdo/kg (Containing/kg) - vit. A - } 15.000 .000 \mathrm{UI} \text {, vit. } \mathrm{D}_{3}- \\
1500.000 \mathrm{UI}(\mathrm{IU}) \text {, vit. } \mathrm{E}-15.000 \mathrm{UI}(\mathrm{IU}) \text {, vit. } \mathrm{B}_{1}-2,0 \mathrm{~g} \text {, vit. } \mathrm{B}_{2}-4,0 \\
\mathrm{~g} \text {, vit. } \mathrm{B}_{6}-3,0 \mathrm{~g} \text {, vit. } \mathrm{B}_{12}-0,015 \mathrm{~g} \text {, ácido nicotínico (nicotinic acid)- } \\
25 \mathrm{~g} \text {, ácido pantotênico (pantothenic acid) }-10 \mathrm{~g} \text {, vit. } \mathrm{K}_{3}-3,0 \mathrm{~g} \text {, ácido } \\
\text { fólico (folic acid)- } 1,0 \mathrm{~g} \text {, bacitracina de zinco (zinc bacitracine) - } 10 \mathrm{~g} \text {, } \\
\text { selênio (selenium) - } 250 \mathrm{mg} \text {, antioxidante BHT (antioxidant BHT) - } 10 \\
\mathrm{~g} \text { e veículo q.S.p. - } 1000 \mathrm{~g} \text {. } \\
2 \text { Conteúdo/kg (Containing/kg): manganês (manganese), } 80 \mathrm{~g} \text {; ferro } \\
\text { (iron), } 80 \mathrm{~g} \text {; zinco (zinc), } 50 \mathrm{~g} \text {; cobre (copper) ; } 10 \mathrm{~g} \text {; cobalto (cobalt), } \\
2 \mathrm{~g} \text {; iodo (iodine), } 1 \mathrm{~g} \text {; e veículo q.s.p., } 500 \mathrm{~g} \text {. }\end{array}$} \\
\hline
\end{tabular}


100 Rev. bras. zootec.

utilizando-se analisador de aminoácidos HITACHI modelo $8500 \mathrm{~A}$.

Foram avaliados o ganho de peso, o consumo de ração, a conversão alimentar, o consumo de lisina, o rendimento de carcaça (\%) e a composição química da carcaça.

Para determinação do rendimento de carcaça, foram utilizadas três aves por unidade experimental, que após 8 horas de jejum foram abatidas. Para cálculo de rendimento de carcaça, considerou-se o peso da carcaça eviscerada, incluindo pés, cabeça e gordura abdominal, em relação ao peso vivo, que foi obtido individualmente antes do abate das aves. $\mathrm{O}$ rendimento de cortes nobres, em que foi considerado rendimento de peito inteiro com pele e osso e pernas (coxa e sobrecoxa com pele), foi calculado em relação ao peso da carcaça eviscerada. Após a avaliação do rendimento de carcaça, as carcaças de cada unidade experimental foram moídas para determinação de sua composição química (matéria seca, extrato etéreo e proteína bruta), segundo os métodos descritos por SILVA (1990).

No $43^{\circ}$ dia, foram coletadas amostras de sangue, utilizando-se três aves de cada unidade experimental para análise de ácido úrico no soro sangüíneo. A metodologia utilizada para padronizar o nível de ácido úrico na corrente sangüínea foi a seguinte: pela manhã retirada da ração por uma hora, retomada da alimentação por uma hora, depois novamente retirada da ração por uma hora, retomada com alimentação por mais uma hora e finalmente um jejum de três horas, em seguida o sangue foi coletado via punção cardíaca. A determinação do nível de ácido úrico no soro sangüíneo foi realizado utilizando-se o URICADKIT do laboratório Biolab-Mérieux.

Utilizou-se delineamento experimental de blocos casualizados com cinco tratamentos - níveis de lisina digestível $(0,80 ; 0,86 ; 0,91 ; 0,97 ;$ e $1,02 \%)$ seis repetições e 15 aves por unidade experimental.

Tabela 2 - Composição em aminoácidos totais dos ingredientes e totais e digestíveis da ração basal ${ }^{1}$

Table 2 - Composition in total amino acid of ingredients and total and digestible of basal diet

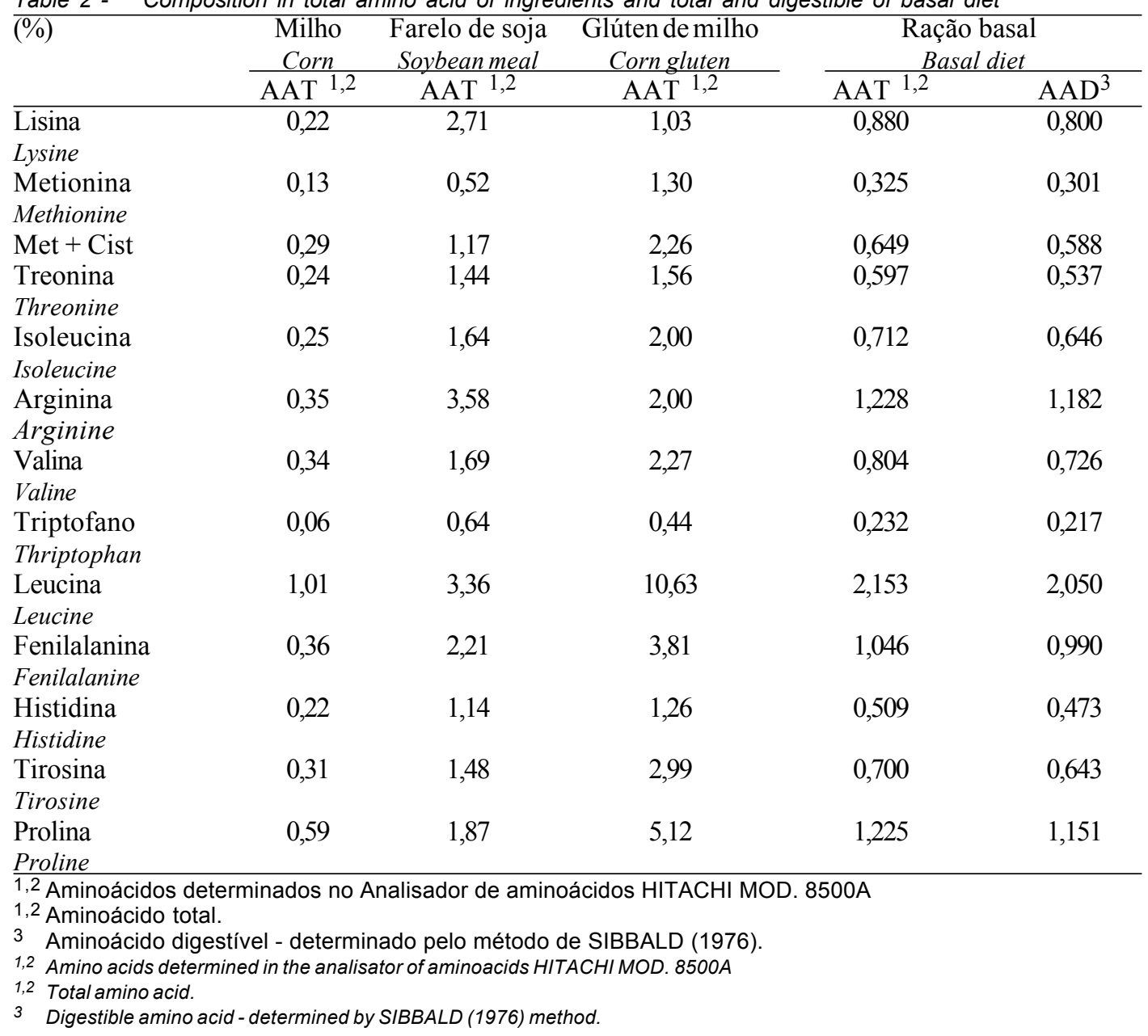


As análises estatísticas das características estudadas foram realizadas utilizando-se o programa Sistema para análise estatística e genética (SAEG 1997), enquanto as estimativas de exigência de lisina digestível foram estabelecidas por meio de modelos de regressão linear e quadrático.

\section{Resultados e Discussão}

Na Tabela 3 são apresentados os resultados de desempenho, consumo de lisina e ácido úrico no soro sangüíneo dos frangos alimentados com diferentes níveis de lisina digestível no período de 22 a 42 dias de idade. Houve efeito $(\mathrm{P}<0,03)$ dos níveis de lisina digestível sobre ganho de peso das aves, o qual aumentou linearmente entre os níveis de 0,80 a 1,02\% de lisina digestível, correspondentes a 0,88 a $1,20 \%$ de lisina total, conforme a equação $\hat{Y}=1228,70+$ 319,023X (Tabela 3 e Figura 1). Estes resultados de exigência estão acima dos $0,85 \%$ de lisina digestível obtidos por HAN e BAKER (1994) e dos 0,85 e 1,00\% de lisina total obtidos por SCHEUERMANN etal. (1993) e Barbosa, (1996), citado por ROSTAGNO et al. (1996), para ganho de peso de frangos de corte no período de 21 a 42 e 22 a 40 dias de idade, respectivamente. No entanto, HOLSHEIMER e RUESINK (1993) obtiveram os melhores resultados de ganho de peso para frangos na fase de 15 a 49 dias de idade, comnível de $1,30 \%$ de lisina total.

Diferenças entre as rações, principalmente com relação à sua composição em aminoácidos digestíveis, as linhagens e o sexo de frangos utilizados nos diferentes trabalhos são fatores que podem justificar as variações de resultados.

Houve efeito quadrático $(\mathrm{P}<0,01)$ dos níveis de lisina da ração sobre consumo de ração (CR), o qual reduziu até o nível de $0,94 \%$ conforme a equação $\hat{\mathrm{Y}}=15994,0-27306,9 \mathrm{X}+14487,2 \mathrm{X}^{2}$. Estes resulta-

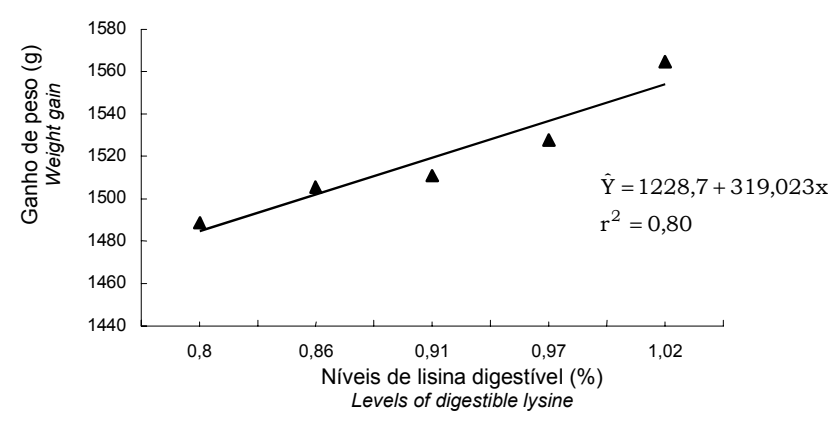

Figura 1 - Níveis de lisina digestível e ganho de peso de frangos de corte machos no período de 22 a 42 dias de idade.

Figure 1 - Levels of digestible lysine and weight gain ratio of male broilers from 22 to 42 days of age.

Tabela 3 - Efeito dos diferentes níveis de lisina digestível sobre desempenho, consumo de lisina e ácido úrico no soro sangüíneo de frangos de corte no período de 22 a 42 dias de idade

Table 3 - Effect of different digestible lysine levels on performance, lysine intake and uric acid in the blood serum of broilers from 1 to 21 days

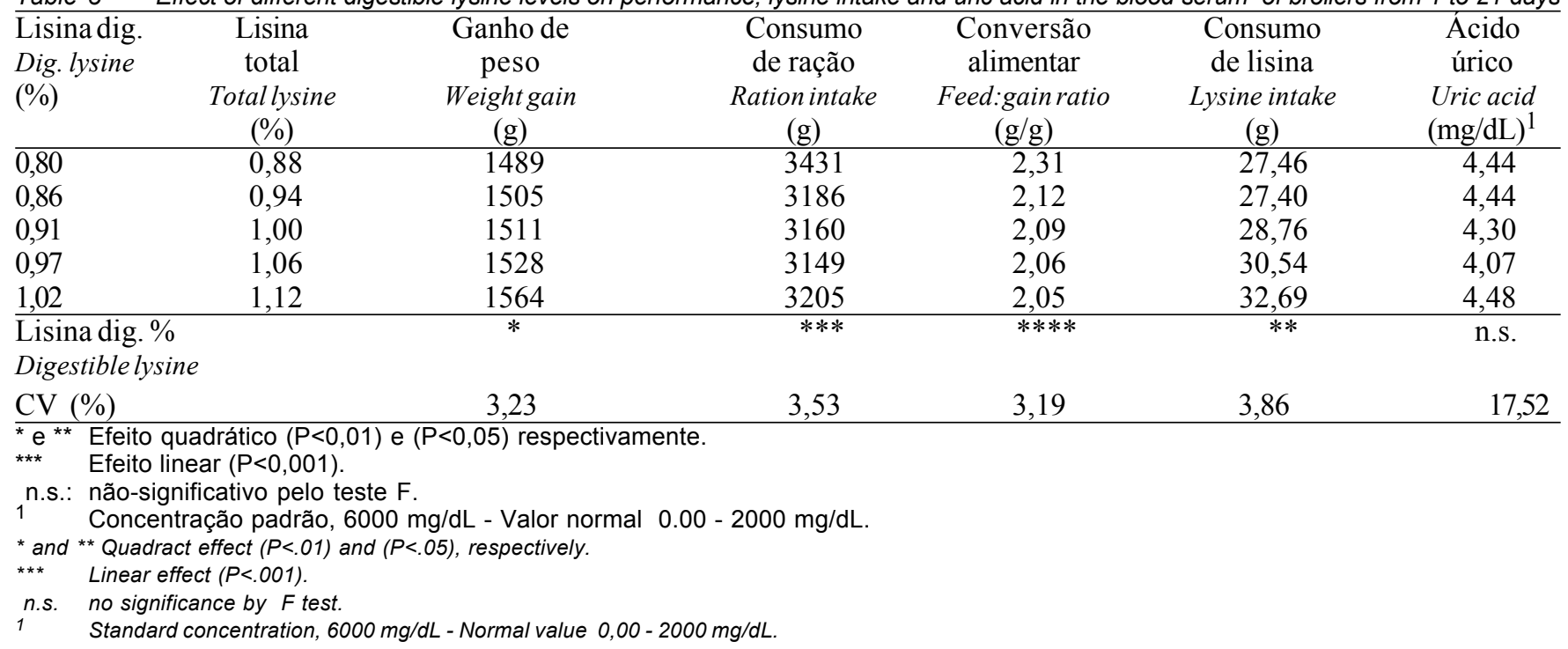




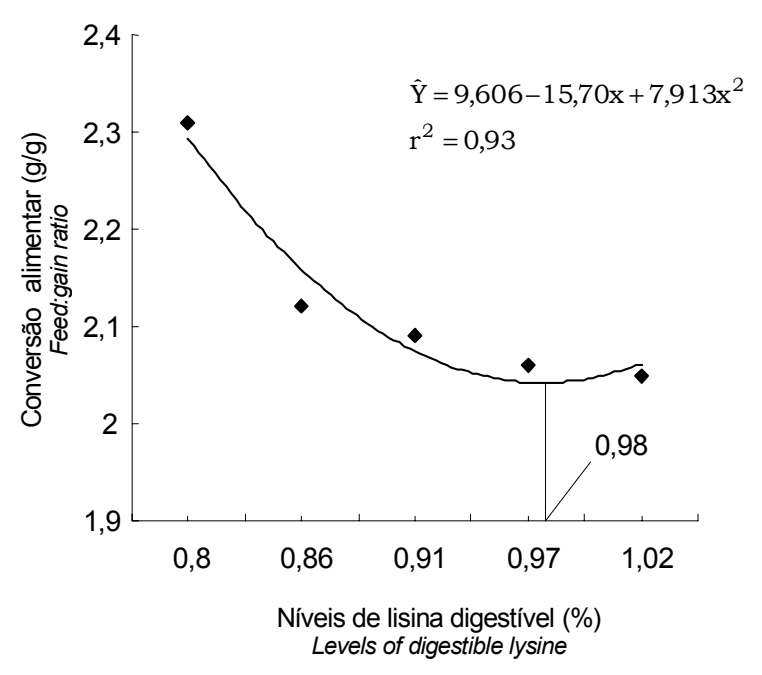

Figura 2 - Níveis de lisina digestível e conversão alimentar de frangos de corte machos no período de 22 a 42 dias de idade.

Figure 2 - Levels of digestible lysine and feed:gain ratio of male broilers from 22 to 42 days of age.

dos foram semelhantes aos obtidos por HAN e BAKER (1994), que verificaram resposta quadrática no CR com níveis crescentes de lisina na ração para frangos no período de 22 a 42 dias de idade. A redução observada no consumo de ração entre os níveis de 0,91 e $0,97 \%$ de lisina digestível pode ter ocorrido em razão da possível melhora gradativa na relação entre a lisina e os demais aminoácidos da ração basal. Como sugerido por Harper (1976), citado por CABEL et al. (1988), os aminoácidos presentes na ração podem alterar o perfil aminoacídico plasmático e regular o balanço energético do animal. Em rações desbalanceadas, o mecanismo que regula o consumo pode estar modificado, podendo ocorrer aumento na ingestão de alimento, em resposta a alterações no metabolismo energético ou em resposta à demanda crescente dos aminoácidos na ração.

Com relação à conversão alimentar $(\mathrm{CA})$, constatou-se melhora $(\mathrm{P}<0,04)$ até o nível de $0,98 \%$ de lisina digestível, estimado pela equação $\hat{\mathrm{Y}}=9,607$ $15,470 \mathrm{X}+7,913 \mathrm{X}^{2}$ (Tabela 3 e Figura 2), correspondente a consumo estimado de 30,85 g de lisina digestível. Este resultado confirma a hipótese de melhora no perfil aminoacídico da ração com o aumento no nível de lisina, anteriormente relatado. No nível de $0,98 \%$, as relações entre a lisina digestível e os aminoácidos considerados críticos para frangos, metionina, treonina, triptofano e arginina, que corresponderam a 41,77, 19 e $115 \%$, respectivamente, que foram próximos aos estabelecidos na proteína ideal por BAKER e HAN (1994), correspondentes a metionina, 37\%; treonina, $70 \%$; triptofano, $17 \%$; e arginina, $105 \%$.

Analisando os resultados de desempenho obtidos, pode-se deduzir que o aumento no ganho de peso entre os níveis de 0,97 e 1,02\% de lisina digestível ocorreu em razão do aumento no consumo de ração, uma vez que a conversão alimentar, embora tenha apresentado resposta quadrática, não variou entre esses dois últimos níveis de lisina avaliados.

Constatou-se efeito linear $(\mathrm{P}<0,01)$ dos tratamentos sobre consumo de lisina no período, apesar de ter ocorrido redução no consumo de ração entre os níveis de 0,91 e $0,97 \%$ de lisina digestível.

Não foi observado variação no nível de ácido úrico no soro sangüíneo das aves, em razão dos níveis de lisina da ração. No entanto, constatou-se que em valores absolutos o nível de ácido úrico diminuiu até o nível de $0,97 \%$ de lisina digestível, que praticamente correspondeu ao que proporcionou melhores resultados de desempenho. Sabe-se que a variação no nível de ácido úrico no soro está relacionada ao metabolismo do nitrogênio, em resposta a concentrações de aminoácidos nas rações (Brown e Cline, 1974 e Fuller et al. 1979, citados por COMA et al. 1995), e que sua redução é associada ao melhor aproveitamento de proteína fornecida.

Os resultados de composição química da carcaça dos frangos abatidos com 42 dias de idade são apresentados na Tabela 4, e os de rendimento de carcaça eviscerada, rendimento de peito e rendimento de pernas, na Tabela 5 .

Não houve efeito dos níveis de lisina digestível sobre a composição química da carcaça. Entretanto, alguns autores (SUMMERS et al., 1992 e DESCHEPPER e GROOTE, 1995) observaram alteração na composição química na carcaça de frangos aos 42 dias de idade, quando utilizaram rações com baixa proteína suplementada com aminoácidos essenciais.

Os níveis de lisina digestível na ração não influenciaram os rendimentos de carcaça (RC), peito (RPT) e perna (RPR). Os resultados de RC foram semelhantes aos obtidos por MORAN e BILGILI (1990), SCHEUERMANN et al. (1993) e KIDD et al. (1997) e os de RPT, aos obtidos por SUMMERS et al. (1988), HOLSHEIMER e RUESINK (1993) e MENDES et al. (1997). No entanto, alguns autores, HICKLING et al. (1990) e HAN e BAKER (1994), 
CONHALATO et al.

Tabela 4 - Efeito dos níveis de lisina digestível sobre composição química da carcaça de frangos de corte no período de 22 a 42 dias de idade ${ }^{1}$

Table 4 - Effect of digestible lysine levels on the carcass chemical composition of broilers from 22 to 42 days of age

\begin{tabular}{lcccc}
\hline $\begin{array}{l}\text { Lisina dig. (\%) } \\
\text { Digestible lysine }\end{array}$ & $\begin{array}{c}\text { MS }(D M) \\
(\%)\end{array}$ & $\begin{array}{c}\text { Água (Water) } \\
(\%)\end{array}$ & $\begin{array}{c}\text { PB }(C P) \\
(\%)\end{array}$ & $\begin{array}{c}\mathrm{EE} \\
(\%)\end{array}$ \\
\hline 0,80 & 34,17 & 65,83 & 17,84 & 13,64 \\
0,86 & 34,51 & 65,50 & 16,79 & 14,64 \\
0,91 & 33,99 & 66,01 & 17,39 & 13,92 \\
0,97 & 33,99 & 66,01 & 18,11 & 13,34 \\
1,02 & 34,31 & 65,69 & 15,83 & 15,33 \\
Lisina dig. (\%) & $\mathrm{ns}$ & $\mathrm{ns}$ & $\mathrm{ns}$ & $\mathrm{ns}$ \\
Digestiblelysine & & & 3,39 & 8,79 \\
CV(\%) & 3,29 & 1,71 & &
\end{tabular}

1 MS - matéria seca, PB - proteína bruta e EE - extrato etéreo.

n.s. - no significance by $F$ test.

1 DM - dry matter, PB - crude protein and EE - ether extract.

Tabela 5 - Efeito dos níveis de lisina digestível sobre rendimento de carcaça eviscerada (RC), rendimento de peito (RPT) e rendimento de pernas (RPR) de frangos de corte aos 42 dias de idade ${ }^{1}$

Table 5 - Effect of digestible lysine levels on the eviscerated carcass yield (RC), breast yield (RPT) and legs yield (RPR) of broilers from 22 to 42 days of age

\begin{tabular}{lcccc}
\hline $\begin{array}{l}\text { Lisina digestível (\%) } \\
\text { Digestiblelysine }\end{array}$ & $\begin{array}{c}\text { Peso vivo (\%) } \\
\text { Weight gain }\end{array}$ & $\begin{array}{c}\text { RCR } \\
(\mathrm{g})\end{array}$ & $\begin{array}{c}\text { PT } \\
(\%)\end{array}$ & $\begin{array}{c}\text { RPR } \\
(\%)\end{array}$ \\
\hline 0,80 & 2123 & 78,59 & 21,63 & 25,94 \\
0,86 & 2168 & 78,48 & 21,86 & 26,19 \\
0,91 & 2133 & 79,28 & 21,45 & 26,08 \\
0,97 & 2153 & 77,64 & 21,56 & 26,48 \\
1,02 & 2190 & 78,24 & 21,87 & 26,06 \\
Lisina digestível \% & $\mathrm{ns}$ & $\mathrm{ns}$ & $\mathrm{ns}$ & $\mathrm{ns}$ \\
CV(\%) & 2,71 & 1,23 & 3,16 & 2,45 \\
\hline
\end{tabular}

n.s. - não-significativo pelo teste $F$.

n.s. - no significance by $F$ test.

encontraram diferenças significativas no rendimento de peito com o aumento do nível de lisina da ração.

De acordo com SIBBALD e WOLYNETZ (1986), o requerimento de aminoácidos essenciais para máximo rendimento de carne de peito está acima do considerado adequado para crescimento. No entanto, neste trabalho, não se detectou melhora no RPT com o aumento do nível de lisina na ração, o que está de acordo com os resultados de SUMMERS et al. (1988), que também não verificaram melhora no RPT com níveis altos de lisina e metionina na ração.

\section{Conclusões}

Nas condições experimentais assinaladas, os resultados de ganho de peso (GP) e conversão alimentar (CA)indicaram estimativa de exigência de lisina digestível na fase de 22 a 42 dias de idade para frangos de corte machos de 1,02 e $0,98 \%$, respectivamente.

\section{Referências Bibliográficas}

ÁVILA, V. S., JAENISCH, F. R. F., PIENIZ, L. C. et al. 1992. Produção e manejo de frangos de corte. Concórdia: EMBRAPA-CNPSA. 43p. (Documentos 28).

BAKER, D. H., HAN, Y. 1994. Ideal amino acid profile for chicks during the first three weeks posthatching. Poult. Sci., 73:1441-1447.

CABEL, M. C., GOODWIN, T. L., WALDROUP, P. W. 1988. Feather meal as a nonspecific nitrogen source for abdominal fat reduction in broilers during the finishing period. Poult. Sci., 67:300 - 306.

COMA, J., CARRION, D., ZIMMERMAN, D. R. 1995. Use of plasma urea nitrogen as a rapid response criterion determine the lysine requirement of pigs. J. Anim. Sci., 73:472-481.

DESCHEPPER, K., DE GROOTE, G. 1995. Effect of dietary protein, essential and non-essential amino acids on the performance and carcase composition of male broiler chickens. Br. Poult. Sci., 36:229-245.

HAN, Y., BAKER, D. H. 1994. Digestible lysine requirement of male and female broiler chicks during the period three to six weeks posthatching. Poult. Sci., 73:739-1745.

HICKLING, D., GUENTER, W., JACKSON, M. E. 1990. The 
104 Rev. bras. zootec.

effect of dietary methionine and lysine on broiler chicken performance and breast meat yield. Can. J. Anim. Sci., 70:673-678.

HOLSHEINER, J. P., RUESINK, E. W. 1993. Effect on performance, carcass composition, yield and financial return of dietary energy and lysine levels in starter and finisher diets fed to broilers. Poult. Sci., 72:806-815.

KIDD, M. T., KERR, B. J., ANTHONY, N. B. 1997. Dietary interactions between lysine and threonine in broilers. Poult. Sci., 76:608-614.

MENDES, A. A., WATKINS, E., ENGLAND, J. A. et al. 1997. Influence of dietary lysine levels and arginine:lysine ratios on performance of broilers exposed to heat or cold stress during the period of three to six weeks of age. Poult. Sci., 76:472-481.

MORAN JR., E. T., BILGILI, S. F. 1990. Processing losses, carcass quality and meat yield of broiler chickens as influenced by dietary lysine. Poult. Sci., 69:702-709.

NATIONAL RESEARCH COUNCIL - NRC. 1994. Nutrients Requirements of Poultry. 9. ed. National Academic Press, Washington, D.C. 155 p.

PUPA, J. M. R. Rações para frangos de corte formuladas com valores de aminoácidos digestiveis verdadeiros, determinados com galos cecectomizados. Viçosa. 1995. 63p. Dissertação (Mestrado em Zootecnia) - Universidade Federal de Viçosa.

ROSTAGNO, H. S. Valores de composição de alimentos e exigências nutricionais utilizadas na formulação de rações para aves. In: REUNIÃO ANUAL DA SOCIEDADE BRASILEIRA DE ZOOTECNIA, 27, Piracicaba, SP, 1990. Anais... Piracicaba: FEALQ, 1990. p. 11-30.

ROSTAGNO, H. S., BARBARINO JR., P., BARBOZA, W. A. Exigências nutricionais das aves determinadas no Brasil. In: SIMPÓSIO INTERNACIONAL SOBRE EXIGÊNCIAS NUTRICIONAIS DE AVES E SUÍNOS, Viçosa, MG, 1996. Anais... UFV: DZO, 1996. p. 361-388.

SAEG - Sistema para análise estatística e genética, Versão 7.0. Viçosa, MG: Fundação Arthur Bernardes, 1997.
SCHEUERMANN, G. N., MAIER, J. C., BELLAVER, C. et al. Exigência de lisina para frangos de corte na fase de 21 a 42 dias de idade. In: REUNIÃO ANUAL DA SOCIEDADE BRASILEIRA DE ZOOTECNIA, 30, Rio de Janeiro, RJ. Anais... Rio de Janeiro: SBZ, 1993. p.314.

SIBBALD, J. R. 1976. A biossay for true metabolizable energy in feedingstuffs. Poult. Sci., 55:303-308.

SIBBALD, J. R., WOLYNETZ, M.S. 1986. Effects of dietary lysine and feed intake on energy utilization and tissue synthesis by broiler chicks. Poult. Sci., 65:98-105.

SILVA, D. J. 1990. Análise de alimentos (Métodos químicos e biológicos). Viçosa: Imprensa Universitária. $160 \mathrm{p}$.

SUMMERS, J. D., LEESON, S., SPRATT, D. 1988. Yield and composition of edible meat from male broilers as influenced by dietary protein level and amino acid supplementation. Can. J. Anim. Sci., 68:241 - 248.

SUMMERS, J. D., SPRATT, D., ATKINSON, J. L. 1992. Broiler weight gain and carcass composition when fed diets varying in amino acid balance, dietary energy, and protein level. Poult. Sci., 71:263 - 273.

Recebido em: 04/02/98

Aceito em: 16/07/98 